\title{
AIDS/EDUCAÇÃO E PREVENÇÃO: PROPOSTA METODOLÓGICA PARA ELABORAÇÃO DE JOGOS EDUCATIVOS ${ }^{1}$
}

\author{
AIDS/EDUCATION AND PREVENTION: A METHODOLOGICAL PROPOSAL \\ FOR THE ELABORATION OF EDUCATIONAL GAMES \\ SIDA/EDUCACIÓNY PREVENCIÓN: PROPUESTA METODOLÓGICA \\ PARA LA ELABORACIÓN DE JUEGOS EDUCATIVOS
}

\author{
Maria Fátima Maciel Araújo ${ }^{2}$ \\ Maria Irismar de Almeida ${ }^{3}$ \\ Raimunda Magalhães da Silva ${ }^{4}$
}

\begin{abstract}
RESUMO: Potencializar recursos educativos para mediar ações de educação em saúde, na prevenção da AIDS tem se constituido um desafio para educadores de saúde. Pela inegável importância desse tipo de material nos espaços propiciadores de aprendizagem, surgiu a proposta com o objetivo de criar um percurso metodológico para elaboração de jogos educativos, com vistas a mediar processos de educação e prevençăo do HIVIAIDS. O estudo se desenvolveu a partir das idéias contidas nos pressupostos da problematização, adaptadas do "método do arco" de Charles Maguerez, com operacionalizaçāo em instituiçōes públicas de saúde e educaçăo, no Estado do Ceará, englobando uma população de escolares (180) na faixa etária de 13 a 19 anos, no periodo de 1995 a 1997. A coleta de dados se deu durante a realização de 04 oficinas, de acordo com o esquema elaborado. Os resultados envolvendo o significado do jogo, ambiente onde se insere e realidade social com abrangência dos sujeitos durante as jogadas, foram problematizados pelos adolescentes e serviram para a formulação de 03 jogos educativos (memorAIDS, baralhAIDS e dominAIDS). As conclusões apontam a proposta como propiciadora do processo participativo, valorizando, em todo o seu percurso, o desenvolvimento da natureza intelectiva e empreendedora, pela mobilização de capacidades humanas e exercicio de associações do universo de exigências relacionados à epidemia de AIDS. Por sua clareza, postulou-se, cientificamente, sua aceitação como percurso metodológico apropriado para elaboração de jogos educativos.
\end{abstract}

PALAVRAS-CHAVE: AIDS, jogos, educação e saúde, enfermagem

\section{INTRODUÇÄO}

Potencializar recursos educativos para mediar ações de educação em saúde tem sido objetivo freqüente entre estudiosos do assunto, que buscam se aproximar, cada vez mais, da idéia de que, em cada realidade é importante que sejam trabalhados seus próprios materiais educativos. Está contido, nessa idéia, o desafio de que, além de prover instituições e grupos desse material é de fundamental importância desenvolver metodologias de elaboração, disponibilizando-as para critica de tantos quantos têm optado por esse segmento da educação em saúde, tão carente desse tipo de estudo.

${ }^{1}$ Prêmio Zaira Cintra Vidal, $1^{\circ}$ lugar, $52^{\circ} \mathrm{CBE}$.

${ }^{2}$ Enfermeira. Professora do Departamento de Enfermagem/UFC. Mestre em Saúde Pública. Doutoranda em Enfermagem.

${ }^{3}$ Enfermeira. Professora do Departamento de Saúde Pública/UECE. Mestre em Educação. Doutoranda em Enfermagem.

${ }^{4}$ Enfermeira. Professora do Departamento de Enfermagem/UFC.Doutora em Enfermagem. 
É inegável o valor desse material para educadores e educandos, pelo seu alto poder de fascinação e inventividade até porque é sempre a partir do seu uso que ocorrem transações pessoais, pondo em destaque a sensibilidade e imaginação criativa de cada um, daí a significativa relevância dos seus aspectos, quando se pensa em processos educativos em saúde.

A opçăo pelo jogo educativo para compor essa proposta dá-se pelo fato de que, há mais de duas décadas, vêm sendo feitos investimentos nesse campo de conhecimento, inicialmente de maneira muito empírica mas, dado o desinteresse crescente nos aspectos de vivências pedagógicas no campo da saúde por educadores e educandos, derivou para a formatação de uma moldura capaz de provocar grandes inquietações, impulsionando investigaçöes nesse campo do conhecimento. Algumas experiências com o uso de jogos educativos mediou processos de ensino-aprendizagem evidenciando capacidades para estimular aprendizagem pela abordagem permeada de maleabilidade e possibilidade de reencantamento e renovaçăo endógenos. A idéia de sair dos "scripts" e ultrapassar a categoria dos determinantes biológicos estabelecidos gerou algumas resistências, superadas, no entanto, pela própria idéia contida nessa forma de trabalho: liberdade de especular, estimulo ao espirito indagador, exercicio da recriação, traduzidos no aprender-raciocinar-criar-comunicar-negociar-decidir. Huizinga (1996, p. 59,62$)$ já ressaltava que "a essência do espirito lúdico é ousar, correr riscos, suportar a incerteza e a tensão; a tensão aumenta a importância do jogo, e essa intensificação permite ao jogador esquecer que está apenas jogando (...) todo jogo ganha de acordo com as regras; todo sacrificio, devidamente realizado está intimamente ligado à aquisição pelo grupo de uma nova prosperidade"; é com base nesse fato, que podemos encontrar a finalidade biológica do jogo, por estar ele sempre vinculado a algo que não é jogo (prazer, protesto, diversão, aprendizagem, poder, etc.).

Kishimoto (1999 p. 9) descreve em seus escritos que o uso do jogo já vem de longas datas, sendo considerado de extrema relevância para a formação do ser humano, sendo elevada sua importância como recurso auxiliar de ensino, fazendo parte, inclusive, das dimensões históricas contidas em contribuiçōes de historiadores (Callois, Huizinga, Áries, Margolin, Mason, Jolibert); filósofos (Aristóteles, Platão, Schiller, Dewey); lingüistas (Cadzen, Vygostski, Weir); antropólogos (Bateson, Schwartzman, Sutton-Smith, Heriot, Brougére); psicólogos (Brunner, Jolly e Sylva, Fein, Freud, Piaget) e educadores (Chateau, Vial, Alain). Revendo essas questőes, encontramos uma diversidade de visōes acerca da compreensão do jogo, na sua especificidade, donde há crença na contribuição que ele pode oferecer aos processos educativos relacionados à educação e prevenção do HIVIAIDS. O recurso é, portanto, muito útil para o desenvolvimento de açōes de enfermagem voltadas para promoçăo da saúde e desenvolvimento de reflexões sobre atitudes de autocuidado.

\section{JOGOS EDUCATIVOS NA EDUCAÇĀO E PREVENÇÃO DA AIDS}

Pensando em AIDS e nos saberes que se constituiram nesse campo, nas últimas décadas, muitos questionamentos se articulam, dando-nos condições de mapear vertentes que elevam o uso do jogo educativo como instrumento de importante referência nos processos de ensinoaprendizagem, com grande significado social no contexto da educação e prevenção do HIV/ AIDS, postulando inclusive, novas formas de pensar a epidemia.

A idèia de fazer do HIVIAIDS foco de discussão, nos espaços pedagógicos, coloca em cena temas antes inquestionáveis (fidelidade, sexo, morte, etc). No entanto, o jogo educativo transporta os jogadores para uma região de alegria e serenidade, o que lhe confere a capacidade de discutir temas desagradáveis dentro de uma perspectiva de encantamento e prazer, em uma parelha complementar de opostos: jogo-seriedade.

O jogo, com suas regras, estabelece uma estreita relação com a epidemia da AIDS, no momento em que, ao delimitar formas de contágio, formas de prevenção, formas de tratamento 
e expectativas de vida, se limita, também, "a um mundo temporariamente circunscrito às suas regras" (Huizinga, 1998, p. 14), onde năo há dúvidas de que a sua desobediência implica conseqüências inabaláveis, frente aos resultados finais conquistados jogo-vida.

O estudo, com o objetivo de criar um percurso metodológico para elaboração de jogos educativos, revestiu-se de grande significado, a partir do instante em que, ao exercitar o processo, os participantes tiveram um grande envolvimento, mediante utilização da dinâmica apropriada, em que o diálogo, a alegria, as dúvidas e os questionamentos eram constantemente realçados.

\section{PROCESSO METODOLÓGICO NA CONSTRUÇÃO DOS JOGOS}

A proposta metodológica se insere em uma tendência problematizadora, sugestiva da escolha do "método do arco" de Charles Maguerez (Bordenave, 1998), na perspectiva de adaptação do modelo, como recurso metodológico, para elaboração de jogos educativos na educação e prevençāo da AIDS, em cujo percurso (Anexo I) estarão contemplados os passos e procedimentos metodológicos de todo seu processo de desenvolvimento.

O estudo, de abordagem exploratório descritivo, desenvolveu-se em uma escola pública estadual do município de Fortaleza, no periodo de 1995/1997, envolvendo uma população de 180 escolares, compreendidos na faixa etária de 13 a 19 anos. A coleta de dados se deu durante a realização de oficinas, "lugar de consertos, descobertas, reparos, lugar de trabalho de construção de vivências e ação. Lugar de vida". Araújo (1998, p. 5) em número de 4, seguindo um percurso metodológico, tendo como referencial de apoio o esquema elaborado, sendo reconhecidos, nessa trajetória: o significado do jogo; o ambiente onde se insere; a realidade social que envolve os sujeitos durante as jogadas. Ao serem problematizadas essas questōes, os adolescentes formularam as idéias contempladas nos jogos denominados MEMORAIDS, DOMIAIDS e BARALHAIDS, ensejando maiores necessidades de aprofundamento teórico, levantamento de dúvidas e questionamentos sobre a epidemia da AIDS; essas idéias foram reavaliadas, a partir das dúvidas e questionamentos apresentados pelos adolescentes e tendo como base teórica o conceito de promoção da saúde e de autocuidado.

Ao discorrermos sobre o percurso do processo, a intenção é explicitar, de forma a mais objetiva possivel, o conjunto de passos e procedimentos para a elaboração dos jogos educativos.

A primeira fase do processo se refere ao "levantar necessidades", no próprio contexto onde os jogadores desenvolvem suas jogadas; essa fase aponta o significado do jogo, na vida das pessoas, vertente considerada importante nos processos pedagógicos, pautados na problematização. Nesse percurso, o jogo é visualizado como parte integrante da cultura do povo, inserido em suas histórias de vida (Araújo, 1997). Huizinga (1996), considera o jogo como o fazem os próprios jogadores, em sua significação primária, tentando compreendê-lo como fator cultural da vida. Ainda como Datner (1995), que estabelece relaçōes entre pessoas e objetos, como parte da própria sobrevivência humana.

A fase Estabelecer campos de atuação, abre possibilidades, no campo educativo, na medida em que se considera a diversidade de jogos encontrados, com indicação de áreas de uso para atendimento as demandas educativas. Quando problematizados, sinalizam, a partir de seus agrupamentos, condições para estabelecer prioridades, remetendo a objetivos mais precisos, em termos de orientação, para elaboração do jogo educativo.

Kishimoto (1994, p. 1-2), aponta que o jogo percorre vários caminhos, indo, por exemplo, o faz-de-conta, simbólico, motores, sensório-motores, intelectuais ou cognitivos, de exterior, de interior, individuais ou coletivos, metafóricos, verbais, de palavras, politicos, de adultos, de animais, de salão, a inúmeros outros, o que mostra a multiplicidade de fenômenos incluidos na categoria jogo.

$\mathrm{Na}$ fase Teorizacão, concorrem várias perspectivas teóricas, envolvidas na criação de "vivências solidárias, novas relações sociais e humanas", com um "tipo novo de conhecimento", 
molhado de existência (Freire citado por Gadotti, 1998). As teorias entram como forma de organização das informações, tornadas compreensiveis e praticáveis, de acordo com a convivência do jogo para a natureza humana como exemplo a Teoria da Rejeição, Teoria da Tolerância, Teoria do Reconhecimento, Teoria da Idealização (Mondin, 1980), dentre outras.

Na fase Hipóteses de Solução, săo relevantes os fatos para composição de ação educativa do jogo, adequando suas propriedades formativas e informativas no campo da educaçăo e prevenção do HIVIAIDS. A idéia se fundamenta no entendimento de que não devem ser impostos modelos únicos, abrindo, por conseguinte, possibilidades para diversificação de idéias de jogos educativos. Tal acontece em se considerando a sua finalidade biológica para o desenvolvimento de processos mentais, articulados na idéia de que o jogo ritualiza o conflito, a luta e o combate, tomados como simbolos da própria vida social, dramática, por essência, mas que pode ser também positiva e prazerosa.

Ao referir a elaboração de projetos de jogos educativos, mais precisamente à sua formulação, após problematização, chama atençăo para a necessidade de leitura da realidade, a qual precisa ser questionada, para compor jogos educativos aptos a mediar processos educativos.

Na educação, a prevenção do HIVIAIDS, como proposta do jogo educativo, precisa ser cuidadosamente testada e avaliada em sua fase "aplicação à realidade", para detectar novas questōes que possam lhe dizer respeito quanto ao enfoque, conceitos expressos, formato, tipos de ilustração e população alvo, de forma que o seu intuito seja satisfeito. Essa fase se constitui relevante para refazer bases de reelaboraçăo, culminando na finalização do jogo educativo e sua adequação aos processos educativos relacionados à problematização da AIDS, em todos os seus contextos familiar, educacional e politicos.

\section{POTENCIALIDADES CRIATIVAS DO ADOLESCENTE NA ELABORAÇÄO DE JOGOS EDUCATIVOS (Resultados) ${ }^{5}$}

Pensar nos resultados do estudo remete-nos à importância de considerar que os adolescentes, no processo de elaboração dos jogos, foram presenças significativas, sendo constantemente realçada sua capacidade criativa, pelas idéias apresentadas e lucidez evidenciadas nas tomadas de decisões frente às dúvidas e questionamentos surgidos, relacionados à vida cotidiana. É importante ser apontado também, que a presença constante de risos, gargalhadas, brincadeiras, em nenhum momento comprometeu a busca do objetivo principal, contido na proposta, e que outro não era se não o de criar idéias de jogos educativos, para mediar discussōes e reflexōes sobre HIVIAIDS.

Ao descrever sobre essas questões mister se faz apontar Castanho (1995, p. 23) que trata em seus escritos "que os adolescentes sempre estão dispostos a jogar e brincar. É fácil uma atividade virar jogo uma conversa terminar em brincadeira, provocação ou gargalhada" enfatizando cada vez mais o que Araújo (1997, p. 61) sugere, "que a idéia de trazer a discussão da AIDS entre adolescente exige uma certa habilidade de observar conteúdos negativos (a AIDS, ainda ligada a morte, promiscuidade, isolamento social) sob formas mais sedutoras". O jogo educativo pode ser colocado, nesse contexto, como uma forma prazerosa para levantar reflexões sobre advertências que hoje já fazem parte de uma nova cara da ainda epidemia. Rosenthal e Scheffer (2000) afirmam que a AIDS não é uma fatalidade; a AIDS pode ser prevenida, tem tratamento e, hoje, é possivel viver dignamente com HIV. Resgatar a visão afirmativa da vida

${ }^{5}$ Os jogos estarāo disponiveis com a autora no endereço: Rua Dr. Ratisbona, 279, bairro Fátima, Fortaleza, CE. CEP 60411-220 
e pensar a AIDS como uma experiência humana, é o desafio contido nos objetivos contemplados nesse kit de jogos educativos. Surgidos naturalmente de um processo planejado, tendo sido marcante a alegria dos adolescentes, quando visualizaram a arte final dos jogos, pelo valor de sua contribuição na luta de controle da epidemia.

A inclusão dos adolescentes, nesse momento, reafirma que quando mobilizados trazem em si o exercicio do prazer, da alegria, da felicidade, importantes elementos de integração e experimento de vida de efeito uns sobre os outros, o que não excluiu, em nenhum instante, a reflexão da AIDS como uma doença mais próxima da vida de cada um em particular. A visão que se iniciou colocando a AIDS como uma doença de "gays", aos poucos foi se modificando para uma compreensăo como doença de "todos nós", que atinge amigos, vizinhos, familiares. Ao mesmo tempo em que ocorriam essas reflexöes, a presença do medo, e desconhecimento sobre a doença ainda se fazia presente. A dificuldade apontada na adoção de medidas de proteção individual e coletiva, foram cedendo lugar a possiveis abordagens no conteúdo de cada jogo em particular. O mito da fatalidade da AIDS, abriu uma perspectiva da necessidade de observar que "a informação sem medo é mais eficaz". Venturi (1992, p. 75) impulsionando os adolescentes a falar de "saúde como não só ter enfermidades, mas dispor de um conjunto de elementos indispensáveis a sua garantia. Mas uma vez o jogo educativo foi de grande representatividade na vida dos adolescentes, pois de suas reflexões, na visão do jogo como estimulante e capaz de proporcionar a diversão, também a aprendizagem". Para eles o jogo educativo propiciou uma maneira de se divertir em conjunto com outras pessoas; neles despertou o raciocinio, criatividade; é saudável para o corpo e para a mente. É mais que lazer faz parte da nossa vida, da nossa cultura pelas suas regras promove a integraçăo e o respeito do próximo.

\section{CONCLUSÕES GERAIS}

O percurso metodológico para elaboração dos jogos, maximizou a valorização do processo participativo em todas as fases. Foi visivel o desenvolvimento da natureza intelectiva e criativa, pela mobilização de capacidades, pelo raciocínio verbal, abstrato, memória visual e o constante exercício de associaçōes do universo de exigências relacionadas à epidemia da AIDS. A proposta, pela sua clareza, revelou-se atraente, cientificamente aceita, como percurso metodológico para elaboração de jogos educativos, voltados para a prevenção da AIDS.

Observamos que o envolvimento dos adolescentes e a forma de chegar à elaboração do jogo educativo, foi de muita riqueza. Tal aconteceu porque, nesse momento, os adolescentes se mostraram dispostos a brincar, a se divertir, permitindo-se, com isso, a vivência de experiências lúdicas, bem como a discussão das interfaces das questōes do HIVIAIDS o que certamente não seria revelado de outra forma.

A metodologia, em todo seu percurso, propiciou o surgimento de um clima intelectualmente estimulante, onde as várias interfaces da AIDS foram reveladas e trabalhadas como conteúdo na elaboração dos jogos educativos: memorAIDS, BaralhAIDS e domiAIDS.

\footnotetext{
ABSTRACT:The development of educational resources to mediate actions in health education and AIDS prevention has been a challenge to health's educators. Due to the undeniable importance of this kind of material in environments favourable to learning, the authors created a methodological proposal to be used in the elaboration of educative games with the purpose of mediating educational measures and the prevention of HIVIAIDS. For theoretical framework, the study relied on the ideas/premises about problem solving, adapted from Charles Manguerez's "arch method", which where put into practice in public schools and health institutions in the state of Ceara, having as study population a group of students (180), aged 13 to 19 years, from the period of 1995 to 1997. Data collection occurred
} 
during four workshops, according to a predefined scheme. The results dealing with the meaning of the game, place of action and social environment were obtained from the teenagers while they were engaged in the games and further analysed by them, resulting in the formulation of (03) educative games (memor AIDS, baralhAIDS and dominAIDS). The authors conclude that the proposal is favourable to participatory action, encouraging during its entire process the development of intellectual and creative skills, by way of mobilizing human capacities and exercising associations related to the AIDS epidemic. Due to its clarity, the authors consider the proposal scientifically acceptable as a methodological guideline for the elaboration of educative games.

KEYWORDS: SIDA, games, education, health, nursing

RESUMEN: Potenciar recursos educativos para mediar acciones de educación en salud en la prevención del SIDA se ha constituido un desafio para los educadores de la salud. Por la innegable importancia de ese tipo de material en los espacios que proporcionan ese aprendizaje, surgió la propuesta, con el objetivo de crear un recorrido metodológico para elaborar juegos educativos para intermediar procelos de educación y prevención del SIDA. El estudio se desarrolló a partir de los presupuestos de la problematización, que se adaptan al "método del arco" de Charles Maguerez, con operacionalización en instituciones públicas de salud y educación, en el Estado de Ceará, y engloban una población de escolares (180) entre los 13 y 19 años, desde 1995 hasta 1997. La recogida de datos ocurrió durante la realización de 04 oficinas, de acuerdo al esquema elaborado. Los resultados que involucraban el significado del juego, ambiente donde se insiere y realidad social de los sujetos involucrados durante las jugadas, fueron problematizados por los adolescentes y sirvieron para la formulación de 03 juegos educativos (memorSIDA, barajaSIDA y domiSIDA). Las conclusiones apuntan la propuesta como propiciadora del proceso participativo y valora, durante todo su percurso, el desarrollo de la naturaleza intelectiva y emprendedora, la mobilización de capacidades humanas y el ejercicio de asociaciones del universo de exigencias que se relacionan a la epidemia del SIDA. Por su claridad, se ha postulado cientificamente su aceptación, como percurso metodológico apropiado para la elaboración de juegos educativos.

PALABRAS CLAVE: SIDA, juegos, educación, salud, enfermeria

\section{REFERÊNCIAS BIBLIOGRÁFICAS}

ARAÚJO, M. F. M. Na luta contra a AIDS. O jogo como esperança de vida. 1997. Dissertação (Mestrado) - Universidade Federal do Ceará, Fortaleza.

ARAÚJO, M.F.M. et al. Como trabalhar com o método de oficinas. Pró-Reitoria de Extensäo, Universidade Federal do Ceará/Universidade Estadual do Ceará. Projeto de Extensão AIDS: Educação e Prevençäo e Projeto de Pesquisa Saúde da Mulher no Cotidiano. Departamento de Enfermagem, 1998. Port Folio.

BORDENAVE, J. D.; FERREIRA, A. M. Estratégias de ensino aprendizagem. Petrópolis: Vozes, 1998.

CASTANHO, G.P. Jogos dramáticos com adolescentes. In: MOTTA S., (Org.) O Jogo no Psicodrama. Sāo Paulo: Ágora, 1995.

DATNER, Y. Jogando a aprendendo a viver. In: MOTTA, S. O Jogo no psicodrama. São Paulo: Ágora, 1995.

GADOTTI, M. As muitas lições de Freire: poder, desejo e memórias de libertação. Porto Alegre: ARTMED, 1998.

HUIZINGA, J. Homo ludens. O Jogo como elemento da Cultura. 4. ed. São Paulo: Perspectiva, 1996. p. 59,62 .

KISHIMOTO, T. M. O Jogo e a educaçāo infantil. Sāo Paulo: Pioneira, 1994. 
MONDIM, B. O Homem quem é ele? Elementos de antropologia filosófica. Tradução de Leal, Ferreira e Ferrari. São Paulo, 1980.

ROSENTHAL, C,; SCHEFFER, M. O novo paciente terminal. Jornal Folha de São Paulo. Tendências e Debates. 24/07/2000.

VENTURI, Z. Muitas idéias na cabeça. In: 1968 o ano que não terminou. Rio de Janeiro: Nova

Fronteira, 1988.

\section{ANEXO I - DIAGRAMA REPRESENTATIVO DO PERCURSO METODOLÓGICO PARA ELABORAÇÃO DE JOGOS EDUCATIVOS}

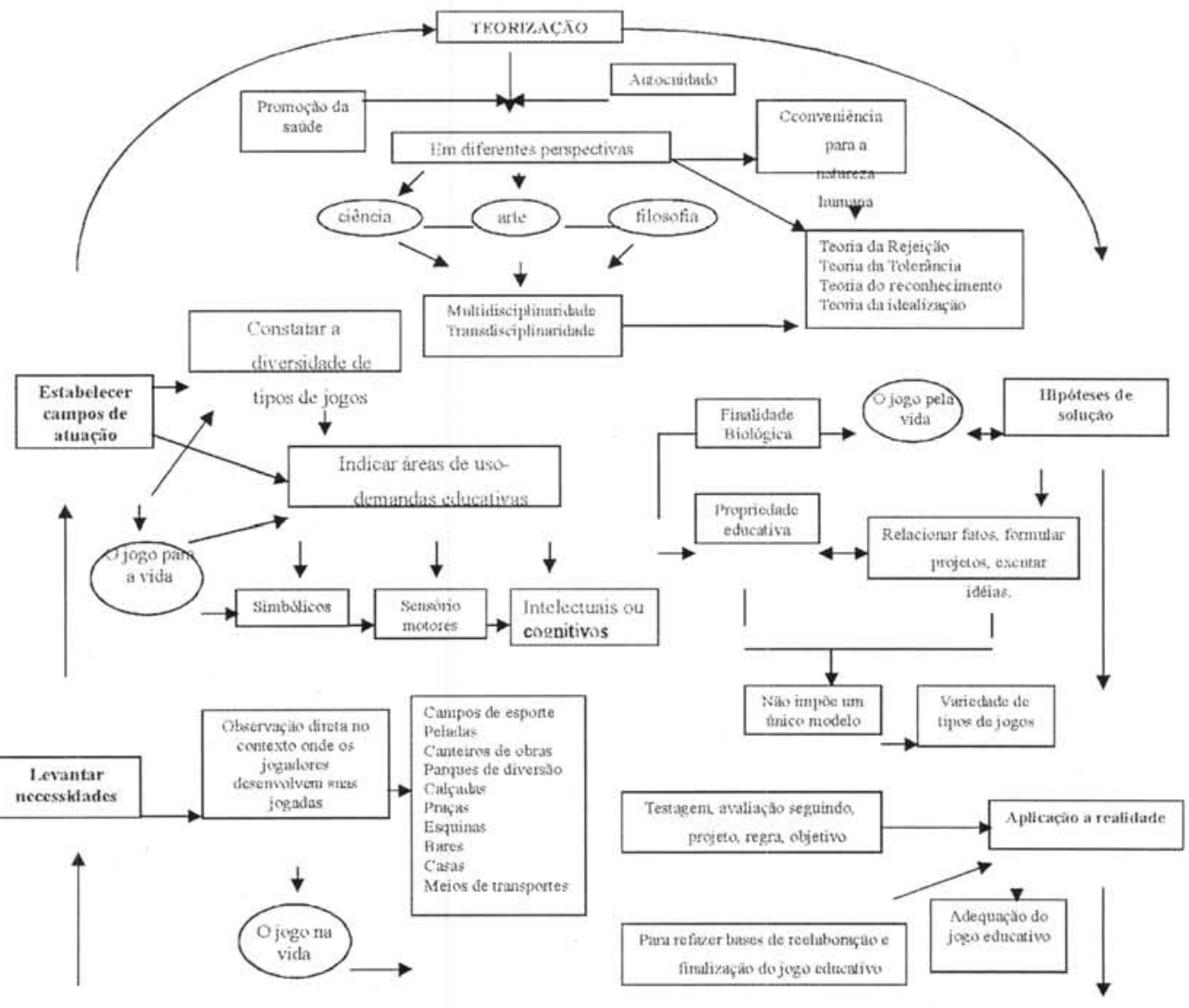

REFATIDADE - O JOGO - PROELIEMTATIZACAO

Adaptado a partir das idéias do método do arco de Charles Maguerez (Bordenave, 1998) por: Maria Fátima Maciel Araújo, Maria Irismar de Almeida e Raimunda Magalhães da Silva

Recebido em outubro de 2000

Aprovado em março de 2001 